\title{
KNOWLEDGE INTENSIVE BUSINESS SERVICES AND THEIR ECONOMIC ROLE IN EUROPEAN UNION: A BRIEF ANALYSIS
}

\author{
Daniel Badulescu*, Alina Badulescu, Sebastian Sipos-Gug, Anamaria Diana Herte, \\ Darie Gavrilut \\ Department of Economic and Business and Doctoral School of Economics, Faculty of \\ Economic Sciences, University of Oradea, Oradea, Romania \\ dbadulescu@uoradea.ro \\ abadulescu@uoradea.ro \\ ssiposgug@yahoo.com \\ dianaherte89@gmail.com \\ darie.gavrilut@gmail.com
}

\begin{abstract}
The decisive role of the knowledge-based economy, and the importance of the ventures fostering the use of innovation and incorporating knowledge, high technology and creativity are nowadays worldwide recognised, even more so considering that the EU is in a permanent search for innovation as a source of and for competitiveness. Knowledge Intensive Business Services (KIBS) are expected to play a key role in the knowledge-based economy as a source of innovation and knowledge in production, dynamic hubs in knowledge-related networks, or intermediaries of innovation between the manufacturing sector and suppliers, partners and final consumers. Within this context, in the present paper we aim to investigate the complex relation between the knowledge intensive business services (KIBS) and the imperative of fostering the economic activity, both of the entrepreneurial dynamics and their macroeconomic effects. The analysis, performed at EU level, leads to interesting results, revealing a complex but contradictory relation between KIBS and economic activity, which is measured by the following main indicators: entrepreneurial density and macroeconomic dynamics.
\end{abstract}

Keywords: knowledge-based services, KIBS, entrepreneurial activity, macroeconomic indicators, European Union.

JEL classification: L84, L86, O33.

\section{Introduction}

The economic transformations of the last decades, both in nature and spatial distribution, are obvious. Fuelled by the major drivers of change, i.e. globalization and the telecommunications revolution (Audretsch, 1998), the national economies have witnessed a new development paradigm, based on innovation and constant adaptation.

The role of innovation and knowledge upon economic growth is not a genuine research theme, but apart from the manufacturing sector, in particular the high-tech industries, only recently have these concepts been associated with the services sector. The perception upon

\footnotetext{
* Parts of this article were presented at The 21st International Scientific Conference "Enterprise and Competitive Environment", March 22-23, 2018, Brno, Czech Republic (Badulescu, Badulescu and Sipos-Gug, 2018), and at The 6th International Conference Innovation Management, Entrepreneurship and Corporate Sustainability (IMES 2018), May 31 - June 1, 2018 Prague, Czech Republic (Badulescu, Badulescu, Sipos-Gug and Herte, 2018).

* Corresponding author: Daniel Badulescu.
} 
services has shifted, evolving from considering them as simple adapters of innovation stemming from the manufacturing sector, to acting as important players in the innovation process, not only as individual innovating actors, but also by spurring on the innovativeness of their clients (Muller and Doloreux, 2007; European Commission, 2012).

In this context of innovativeness and development, the research interest focuses on a specific part of the service sector, the so-called knowledge-intensive services (KIS) and specifically on their subfield named knowledge-intensive business services (KIBS), i.e. the sector including companies providing knowledge-intensive (goods and) services for other companies. Defining KIBS as services where 'knowledge is the main production factor and the good they offer' (European Commission, 2012: 6), the researchers consider that their approach can enrich with different features of KIBS, such as: in-depth interaction between supplier and user (Muller and Zenker, 2001), problem solver by adapting their expertise and knowledge to the need of the client (Strambach, 2008), capable to "generate, facilitate or adopt technological, organisational, social or other kinds of innovation" (Merino and Rubalcaba, 2013:218). Finally, other researchers, approaching the role of "business angels" in boosting businesses, link the KIBS with the presence of the so-called "knowledge angels", i.e. individuals, persons whose "motivations, talents and specific activities play a specific role within the innovation processes of these firms" (Muller et al., 2012a: 36), "a creative knowledge broker responsible for most of KIBS' efficiency in the global innovation process" (Muller et al., 2012b: 2), acting as "innovation catalysts" within KIBS (European Commission, 2012: 7).

This paper investigates the role of knowledge-based business services (KIBS) in fostering the entrepreneurial activity and macroeconomic results at EU level. It is organised as follows: in the first part we review the relevant literature; in the second part we present the research methodology, including data sources, the indicators used and the research hypotheses; in the third part we present and discuss the relationship between KIBS and the dynamics of the entrepreneurial activity (including the risk of firms discontinuing their activity) and between KIBS and some selected macroeconomic indicators (labour productivity and GDP). The last part presents the findings and conclusions on the complex relationships between these phenomena, as they result from our research.

\section{Literature review}

New venture creation as a process based on a novel business idea, an innovative product or an experiment that allows (following a visionary leader) to overcome the competitors, is a central element of entrepreneurship theories (Casson, 2005; Shane and Venkataraman, 2000). However, Autio and Acs (2007) or Wennberg (2010: 2) avoid to confer to all forms of entrepreneurship (particularly to self-employment and less innovative entrepreneurship) the feature of innovation and knowledge. They focus on "high-potential entrepreneurship" which is the one that really matters for economic development. Younger knowledge and innovation-based firms contribute to the economic growth because they are in entrepreneurial alert and oriented (Lumpkin and Dess, 1996), they do not value excessive internal procedures and routines and take quick decisions in order to adapt to a changing business environment. Moreover, Rosenbusch (2011) considers that the relation between innovativeness and business performance has stronger result in small and young firms. Wennberg, citing Agarwal et al (2010), considers that the essential link between entrepreneurship (as an opportunity for knowledge spill-over, but also for new venture creation) and intensive knowledge is that "knowledge from technological change can be seen as a non-rival and partially excludable good" (Wennberg, 2010: 22). The newly created firms and the established firms that have made the shift from a manufacturing to a service 
intensive economy were the actors of the explosive growth of knowledge-intensive business services (Wennberg, 2010).

Moreover, Lever (2002), Malecki (2007), Varis et al (2014: 102) consider that ignoring the contribution of entrepreneurship and new business formation in the new knowledge-based industries will affect the competitiveness of the economies of the world, regardless of their current level of development. EU policies and strategies insist on a knowledge-based economy, by fostering entrepreneurship and by the commercialization of new technologies (Audretsch et al., 2009; Varis et al., 2014: 102) while Wong et al. (2005) consider that highpotential innovative start-ups contribute positively to economic growth to an extent even greater than the undifferentiated support for the creation of new firms. However, recent research shows that it is difficult to endorse a direct relationship between KIBS sector incentives, the creation of new ventures and the economic growth revival in some areas. In their study on the recent development of the knowledge-based industries in a relatively small and remote Finnish region, Varis et al (2014: 119) have found out that "even if the basic elements for industrial renewal and diversification - firms, basic and applied research, financial institutions, commercialization services etc. - seem to be in place", the development of knowledge-based industries or of the regional economy, as a whole, is not impressive. Researchers hypothesize that in the new era of technology, communications and information, the location of KIBS companies cannot have significant effects on local low-tech industries, as long as their functional relationships are not spatial dependent or motivated by them. At the same time, they question the local, national or EU level policies that consume high amounts of funds on impossible targets, counting on a hypothetical multiplier effect of KIBS in the less developed regions. With all the modernity and paradigm shift brought by KIBS to entrepreneurship, many authors point out that this sector should not be overestimated and considered as a universal panacea to the problems of unequal regional development, deindustrialization or lack of resources and opportunities. Thus, in a study of regions affected by the recession and deindustrialization in the United Kingdom, Savic (2016) shows that KIBS sector can be involved so as to mitigate the lack of jobs and to restore the economic base in these areas, but that their effect is partial and that the value added and impact is significantly lower than that of their equivalent companies located in metropolitan centres. Moreover, KIBS, by their de-localization capacity, can contribute, directly or indirectly, to the dislocation, or even the dissolution, of the other local industries that have survived the wave of deindustrialization of the last decades. By default, a continuous spiral of diminishing processing industries could occur and, implicitly, the demand for services addressed to local KIBS will decrease, which will lead to the reduction of this sector as well. In other words, in deindustrialized regions (and probably in other relatively similar situations) KIBS cannot be a stable, long-term substitute for loss of income and jobs in the manufacturing, financial and public service sectors. Moreover, central and local public authorities are beginning to realize that a wide range of broad, structural and consecutive phenomena - recession, continuous deindustrialization and job losses in the public sector cannot be solved with partial KIBS solutions, and that policies must include wider and deeper measures.

In another research aiming at finding characteristics of young creative companies that enhance their innovation and the use of knowledge-intensive business services (KIBS), Mas-Tur and Ribeiro Soriano (2014) investigate if the government should consider this type of company as being a target for their innovation policies (through subsidies, promotion of infrastructure and knowledge transfer etc.). The reasons for public support are that KIBS could foster unspecific entrepreneurship, could act as enablers and sources of innovation for companies from different sectors, irrespective of the fact that KIBS enhance innovation mostly in companies that are, by definition, innovative (Audretsch, 2012; Mas-Verdu et al., 2011). Hyytinen et al. (2015) consider that public policies aimed at supporting innovative 
start-ups in high-tech fields or KIBS should not exaggerate with the argument that innovating ventures are more likely to survive than other start-ups (on the contrary, they say!) and create stable jobs (Hyytinen et al., 2015: 565). The authors consider (without denying other reasons for supporting innovation) that innovativeness should not be seen by entrepreneurs, or by advocates of public supportive policies, as a form of insurance against failure in the start-up phase (Hatos et al., 2015). On the other hand, the access to knowledge can represent a chance for ambitious and experienced entrepreneurs from different sectors (not necessarily high knowledge sectors). In a research centred on highlighting the role of dynamic capabilities, Karagouni and Kalesi (2011) show that mature firms from low-tech sectors "with strong and versatile dynamic capabilities that build on knowledge have more chances to survive and prosper in a globalized economy" also gain competitive advantage and adapt to customer needs, together with those still based on conventional products or processes or low price strategies (Karagouni and Kalesi, 2011: 14-15). Innovation (fuelled by technological progress and the striving for quality and competitive prices), speed of delivery and proximity to customers are elements that define SMEs in the KIBS sector. However, the relationship between KIBSs and innovation is not always strong and unconditional, as it seems in theory. For many SMEs in this sector, the appetite for innovation is often moderated by maintaining a reputation for stability in relation with traditional corporate clients, by maintaining a more conservative attitude on established quality of existing services and even by a protected market for young new entrants (Corrocher et al., 2012) or to those from peripheric regions or sectors.

The research on the relationship between innovation, intensive knowledge and entrepreneurship does not cease at the stage of creating new companies, but this relationship also makes sense when talking about their closure. Thus, discontinuing a business does not necessarily indicate that all fruits of its innovative efforts are wasted (Hyytinen et al., 2015). KIBS firms could generate lasting local knowledge spill-overs, regardless of whether these companies have had continued success, or they have shut down. The knowledge spill-over theory of entrepreneurship (Acs et al., 2009) asserts that new knowledge stimulates venture creation and new market entry. Moreover, the closure of a company that was promoted and which has used innovation and knowledge does not automatically mean an empty seat in the local economy and society. It leaves behind resources (e.g. qualified employees, specialized assets, business ideas) that may facilitate (directly or indirectly) the launch of new firms (Pe'er and Vertinsky, 2008). The essential argument regarding the link between KIBS and business creation is that they produce positive intertemporal and spatial externalities (Hyytinen et al., 2015: 577).

Regarding the issue of labour productivity, scholars are relatively unanimous that the service sector presents itself, with few exceptions, with a lower productivity than compared to the industrial sector. However, it is questionable to apply the industrial concept of productivity to services, due to their specific characteristics (e.g. intangibility, heterogeneity, strong connectivity to customers and the high importance of human factor). The discussion is complicated when considering the contribution of the service sector to labour productivity growth on the economy as a whole, or referring to the relationship between clients' perceived quality and productivity. Moreover, according to Akehurst (2008: 8), the services' productivity "is not either so low or slowly increasing as it is possible to understand from the indicators of the national statistics". With regard to macro-economic reasons, it can be argued that innovation induced by knowledge (intensive) services raise productivity and fosters innovation in general. However, the participation of firms from service sector in R\&D programmes is relatively low, as compared to their economic share (European Commission, 2012: 33). Knowledge intensive business services often accompany regional prosperity and innovation, and wealthy regions are typically characterized by a considerable high concentration of KIBS, "explaining almost $59 \%$ of variance in GDP per capita" (Europe 
Innova, 2009). Regions with high concentrations of KIBS exhibit superior patenting activity, which shows that, beyond other factors able to explain labour productivity in certain sectors or regions, the presence of KIBS is really noticeable.

It is interesting to see in what way the notions, consideration and ideas regarding KIBS have evolved over time. Several authors have proposed that up until 2020, there will be four scenarios that KIBS companies could undertake, namely: the technology driven scenario, network and systems scenario, service driven scenario and procurement driven scenario (Toivonen and Caru, 2016). It is important to note that these scenarios are not fixed, and that KIBS companies can alternate amond these scenarios. As shall be concluded from the following part of this research paper, these scenarios have now become realities in which companies operate.

\section{Research methodology}

\subsection{Data and measures}

We used as an indicator of KIBS density the share of companies from the KIBS sector in the total number of active companies, every year, for each country in the study. The data was obtained from EUROSTAT data-base and it covers the EU27-member countries over the 2008-2012 period. Before 2008, the NACE 1.1 system was in use and data regarding the number of active companies is only available as according to it. The correspondence between NACE 1.1 and the currently used NACE Rev. 2 classification system does not allow a continuous time series to be build regarding the share of KIBS companies into the total number of active companies in each country, every year.

Regarding the definition of the analysed KIBS, we must mention that we have included in the analysis a number of 10 NACE Rev. 2 codes, as described in Table no. 1. The selection of these codes was based both on theoretical considerations (see Schnabl and Zenker, 2013; European Commission, 2012: 12), but also based on data availability constraints, since data for some codes that we initially planned to consider were only available at the class level.

Table 1: Classification of KIBS activities according to NACE Rev. 2

\begin{tabular}{|c|c|}
\hline $\begin{array}{lll}\text { NACE } & 2 & \text { Rev.2 } \\
\text { codes } & & \end{array}$ & Description \\
\hline J62 & $\begin{array}{l}\text { Computer programming, consultancy and related } \\
\text { activities }\end{array}$ \\
\hline J63 & Information service activities \\
\hline M69 & Legal and accounting activities \\
\hline M70 & $\begin{array}{l}\text { Activities of head offices; management consultancy } \\
\text { activities }\end{array}$ \\
\hline M71 & $\begin{array}{l}\text { Architectural and engineering activities; technical testing } \\
\text { and analysis }\end{array}$ \\
\hline M72 & Scientific research and development \\
\hline M73 & Advertising and market research \\
\hline M742 & Photographic activities \\
\hline M743 & Translation and interpretation activities \\
\hline N782 & Temporary employment agency activities \\
\hline
\end{tabular}

Source: EUROSTAT, 2008

By considering the mentioned the KIBS activities, a first observation is that the density of KIBS enterprises in the total active companies at the EU level presents major differences 
between countries, with values starting at $10-11 \%$ in countries like Bulgaria and Cyprus, and reaching $25-30 \%$ in countries like Sweden and the Netherlands.

Regarding the other indicator that we have included in the study (namely entrepreneurial activity and labour productivity) we also resorted to the data available from EUROSTAT. Therefore, in the case of entrepreneurial activity, we used the EUROSTAT data regarding the number of new / closed companies and labour productivity (the turnover per /employed persons).

In respect to the geographical coverage of the study, we have analyzed new/closed companies, yearly, from the EU member states. As an indicator of the labour productivity, we have used the turnover per person-employed data, also available in the EUROSTAT database. Due to missing data, we have eliminated in the stage a number of three countries, namely Greece, Denmark and Malta, and therefore in the next analysis stage we have only tested our proposed models on a total of 24 countries.

Data analysis was performed using R 3.0.3 "plm" package, developed specifically for panel data linear regression analyses (Croissant and Millo, 2008).

\subsection{Hypotheses}

The hypotheses formulated and then tested in this paper, by using the data sources previously mentioned, are as follows:

$\mathrm{H} 1$ : KIBS act as a stimulating factor for the entrepreneurial activity;

$\mathrm{H} 2$ : KIBS act as a blocking factor for the number of closed companies;

H3: KIBS act as a factor fostering the growth of labour productivity within the companies.

\section{Results and discussion}

\subsection{The relation between KIBS and the entrepreneurial activity}

Regarding the share of the companies acting in the KIBS sectors in the total number of active companies, analysed as a stimulating factor for the number of newly registered companies per 1,000 inhabitants of working age, each year, in the investigated countries (EU 27, excluding Greece, Denmark and Malta), the results of the preliminary analysis did not yield a valid model. The value of the ANOVA test $F(1,95)=0.072$, for this model, having an associated $p$ value of 0.79 . In this case, we cannot claim that KIBS acts as a factor for the entrepreneurial activity in the EU.

Refining the analysis by investigating the entrepreneurial activity at sectoral level for industry (i.e. total industry and manufacturing industry) and for construction sector also did not yield valid models. Usually, we expect a finer level analysis to reveal some relations that might be missed in a more general analysis; however, in this case, no arguments were found to support any influence of the share of the companies activating in the KIBS sector on the entrepreneurial activity, neither on a general basis or on a sectoral level (i.e. industry or construction). By considering the nature of the industry in general, and of the manufacturing industry in particular, the existence of the KIBS companies could be a motivating factor for starting up new companies (by taking innovation and implementing it into production); however, their impact does not seem to be significant at the level of the investigated countries.

In Figure no. 1 we present a graphical representation of the relationship between the share of the KIBS in total companies and the number of newly registered companies, for the investigated EU countries. The results of the local regression analysis, according to the "loess" method proposed by W. S. Cleveland, E. Grosse and W. M. Shyu (1992), are also presented in Figure no. 1. Due to the limitations of this method in the case of the available 
data (covering only 5 years), this analysis is shown with the purpose of easing the interpretation of graphical data.

Within the $13-17 \%$ interval for the share of KIBS companies in total companies, we notice a higher variability of the entrepreneurial density, as in this case the number of newly registered companies per 1,000 work-age people varies between 1 and 20, while in the case of the rest of the time series the amplitude is lower. This could be an indicator of a certain connection at the level of the said interval. However, it could also be the result of a higher number of countries presenting shares of KIBS companies in the total active companies within this $13-17 \%$ interval. More studies are required in order to better investigate this aspect, as more data will be available and time series will be long enough to allow more complex analyses.

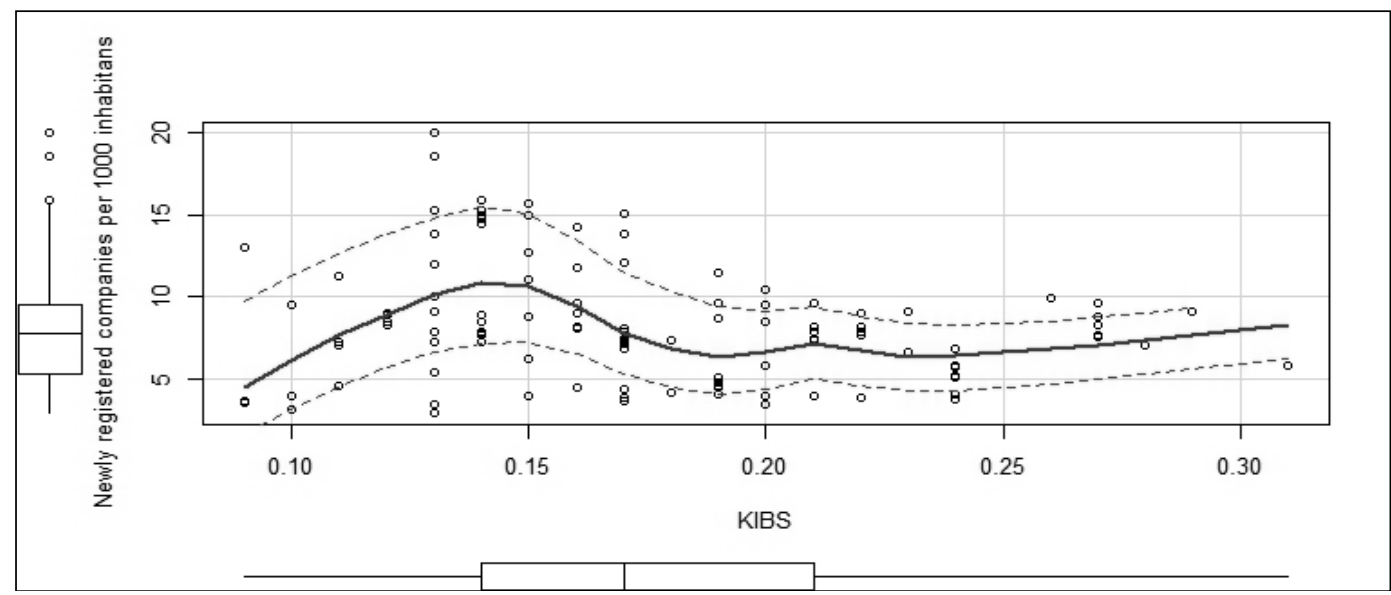

Figure 1: The relation between the share of KIBS in the total number of active companies and the total number of newly registered companies per 1,000 inhabitants

Due to the inconclusiveness of the partial results, we decided to go further and detail the relation between the two variables at level of the EU countries included in the analysis (for the same 2008-2012 time period). Due to the relatively short time series (i.e. 5 years), our conclusions are limited. However, we can notice that some countries (e.g. Cyprus, Latvia, Luxembourg and Romania) display relatively strong correlations, in a positive direction, between the share of KIBS companies in the total active companies, and the entrepreneurial activity, i.e. a high share of KIBS is related to an increase of the entrepreneurial activity. At the same time, in countries such as Bulgaria, Estonia, Hungary, Poland, Netherlands and Slovenia, the correlation is negative (i.e. a high share of KIBS is related to a decrease of the entrepreneurial activity). Data indicates that the relation displays different magnitudes in the investigated EU countries, even having opposed directions. These results require further investigations in order to determine the elements that mediate and/or moderate the relations between KIBS and entrepreneurship. Of course, there is a possibility that no relation actually exists at EU level, that the two variables are being influenced by other factors, which are dependent on each country's economical characteristics.

\subsection{The relation between KIBS and the number of closed companies}

The analyses performed have indicated that the share of KIBS companies in the total active companies exercise a negative influence on the number of closed companies per 1,000 work-age inhabitants, in the selected EU countries, for the five investigated years (Figure no 2). The tested model is one of linear regression, applied to panel data (ANOVA test for the model is $F(1,92)=8.202$ with an associated $p$ value of 0.01 . The coefficient of this relation 
is $b=-36.847$, therefore we can claim that an increase of $1 \%$ in the share of KIBS in total companies is associated with a decrease of almost 37 of the number of closed companies per 1,000 inhabitants. In the case of the investigated countries, an increase of $1 \%$ of the share of KIBS in the number of total active companies should lead to a number of 118,000 companies continuing their activity, rather than discontinuing it, for each year.

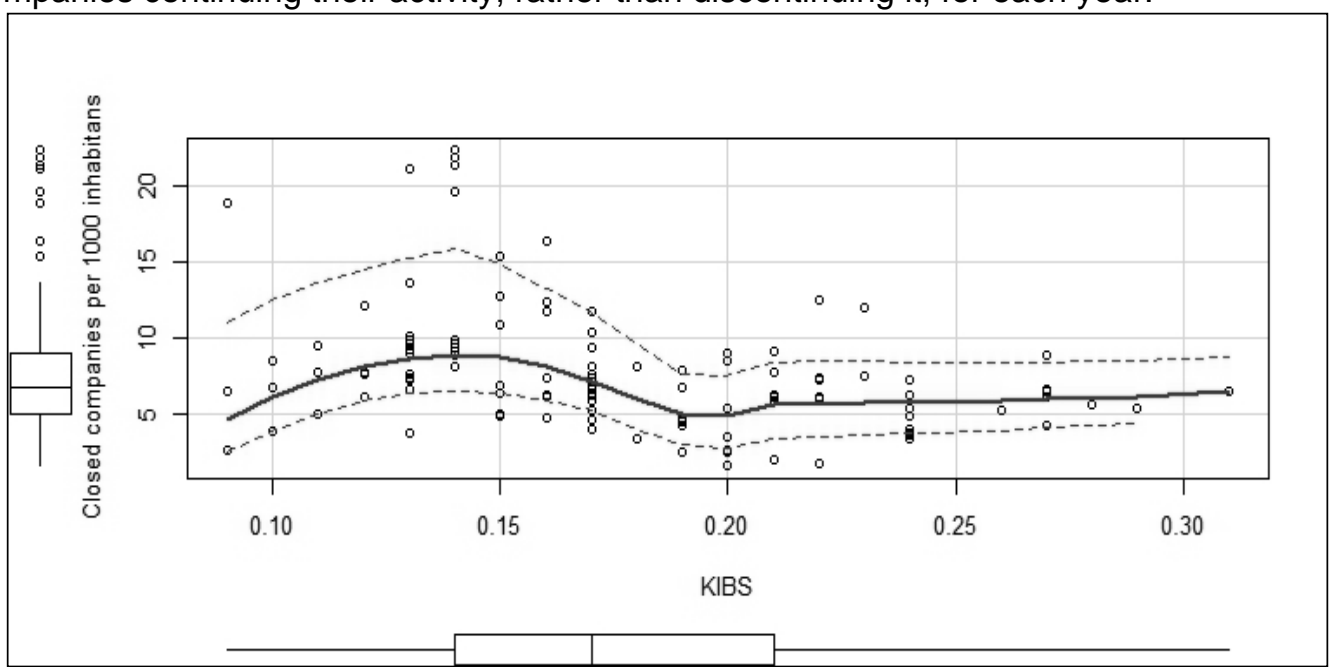

Figure 2: The relations between the share of KIBS companies in the total active companies and the number of companies closed down per 1,000 inhabitants

We also looked at a series of other factors that could influence the discontinuing of the companies, including GPD (starting from the premise that a decrease in GDP has a negative impact on the business from a demographical perspective), the entrepreneurial activity of the previous year and the productivity of the companies; however, none of these led to a valid regression model.

The relation holds in the case of sectoral analyses, namely in the case of (total) industry, manufacturing industry, and construction. The model validation analyses are presented in Table no. 2. The three models have similar characteristics from the point of view of the explained variance in the number of closed (discontinued) companies by KIBS density $(\sim 10 \%)$. The coefficients for industry and manufacturing industry are similar, suggesting that an increase of $1 \%$ of the share of KIBS in total companies would lead to a decrease of 4.45 in the number of companies closed per 1,000 inhabitants. In the case of the construction sector, the impact is even stronger, with an increase of $1 \%$ of the share of KIBS in total companies leading to 11.64 fewer companies closed per 1,000 inhabitants in the construction sector.

Table 2: The results of panel regressing of the KIBS density on the number of closed companies per 1,000 inhabitants

\begin{tabular}{|l|l|l|l|l|}
\hline Dependent & ANOVA F (1,91) & $\mathbf{P}$ & $\mathbf{R}^{\mathbf{2}}$ & Coefficient \\
\hline Total companies & 8.202 & 0.01 & 0.08 & -36.847 \\
\hline Industry (total) & 10.312 & 0.002 & 0.10 & -4.45 \\
\hline Manufacturing industry & 11.886 & $<0.001$ & 0.12 & -4.55 \\
\hline Constructions & 10.6342 & 0.001 & 0.10 & -11.641 \\
\hline
\end{tabular}

\subsection{The relation between KIBS, labour productivity and GDP}

Following the previous analysis, we looked at the relation between GDP and the share of KIBS. We found that GDP per capita is not a significant factor for the evolution of the share 
of KIBS in the total number of active companies throughout the investigated countries (EU 27 with the exception of Greece, Denmark and Malta; the ANOVA test of the model is F ( 1 , $95)=0.527$ with a $p$ value of 0.47 . The data reveals that Luxembourg is an outlier, due to its high GDP value. Therefore, we decided to run the analysis again by excluding it. Even so, no valid regression model was found $(p=0.66)$.

Figure no. 3 shows the results of the analysis of "loess", which indicated the possibility of a non-linear relationship between the share of KIBS in total active companies and GDP. A second order (quadratic) model was also tested, but rejected in the case of the whole sample of countries $(p=0.73)$ and in the case of the sample with Luxembourg excluded: $(p=0.21)$. Therefore, the change in the share of KIBS in total active companies is apparently independent of the level of the aggregated macroeconomic indicator GDP.

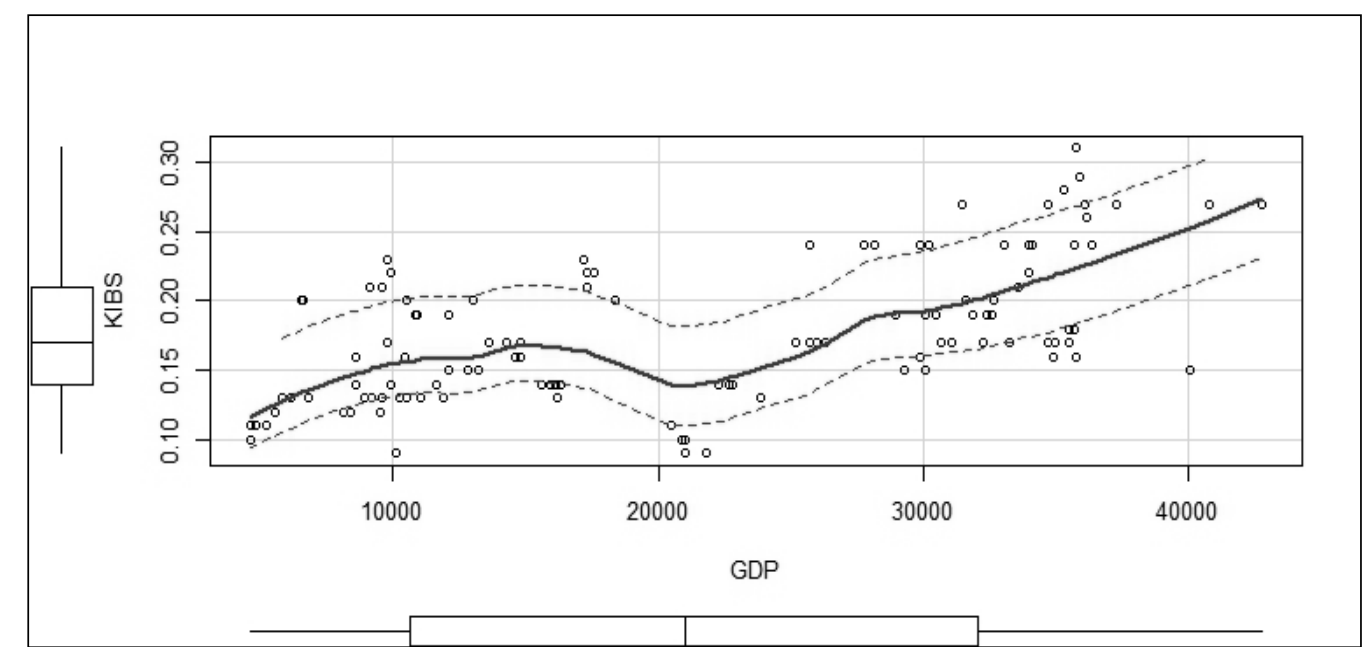

Figure 3: The relation between GDP and the share of KIBS companies in total active companies

We have however found that the share of KIBS is a significant factor of labour productivity within the companies in the sample of countries (EU 27, except for Greece, Denmark and Malta). The ANOVA test of the regression model $F(1,95)=4.316$ has an associated $p$ value of 0.04 . If we look at the relation between the share of KIBS and the labour productivity if analysed in the context of including GDP as a factor of the productivity, the resulting model is also valid $(F(1,95)=41.837, p<0.001)$. At the same time, the model is more efficient than the model including only KIBS. It explains $47 \%$ of the variance in productivity, as compared to $4 \%$ in the case of the simple model $\left(R^{2}=0.47\right.$ versus $\left.R^{2}=0.04\right)$. 


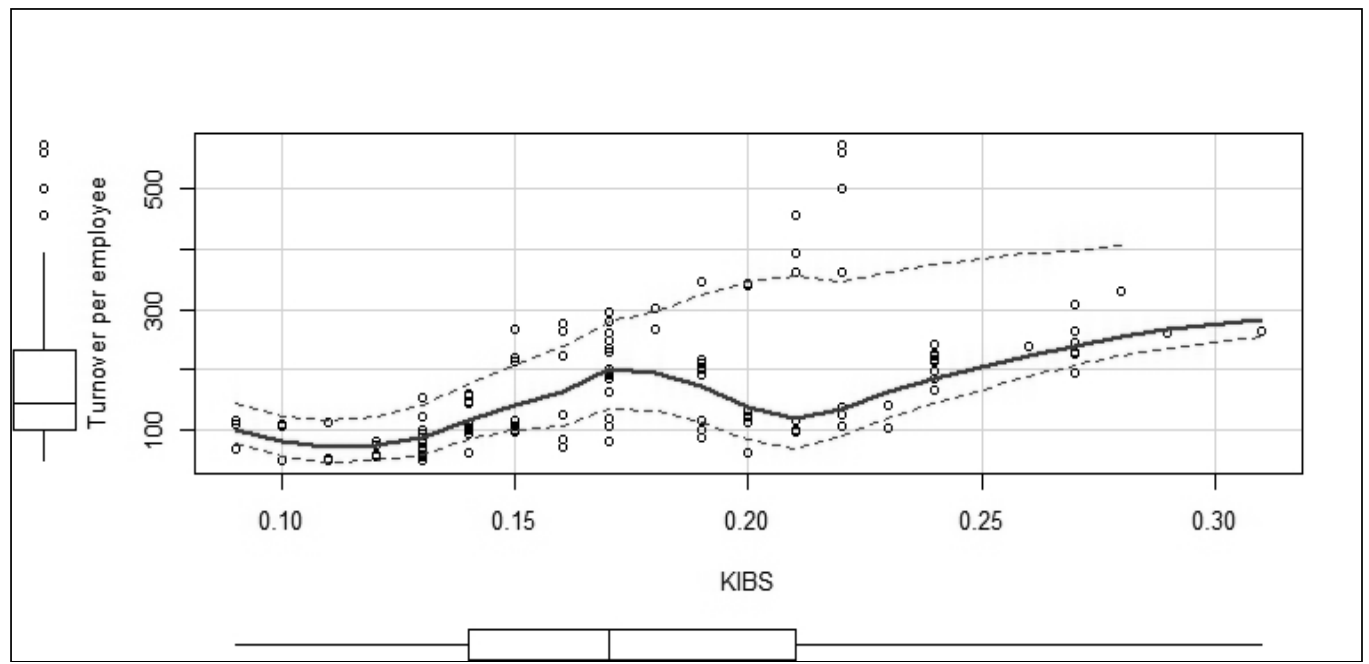

Figure 4: The relation between the share of KIBS in total active companies and the labour productivity in all companies

Figure no. 4 allows us to look closer to this relation, that has a relatively high variability, but a definite upwards trend. It would seem that a higher share of the KIBS companies in the economy allows for the reach of higher levels of productivity. However, the relative constant level of the minimum level of the local regression (i.e. the lower dotted line) suggests that this relation is influenced by other factors as well.

One such factor is GDP, which is (predictably) related to the labour productivity, measured by the turnover per employee. Figure no. 5 allows us to visualize this relation, which seems to be linear and positive.

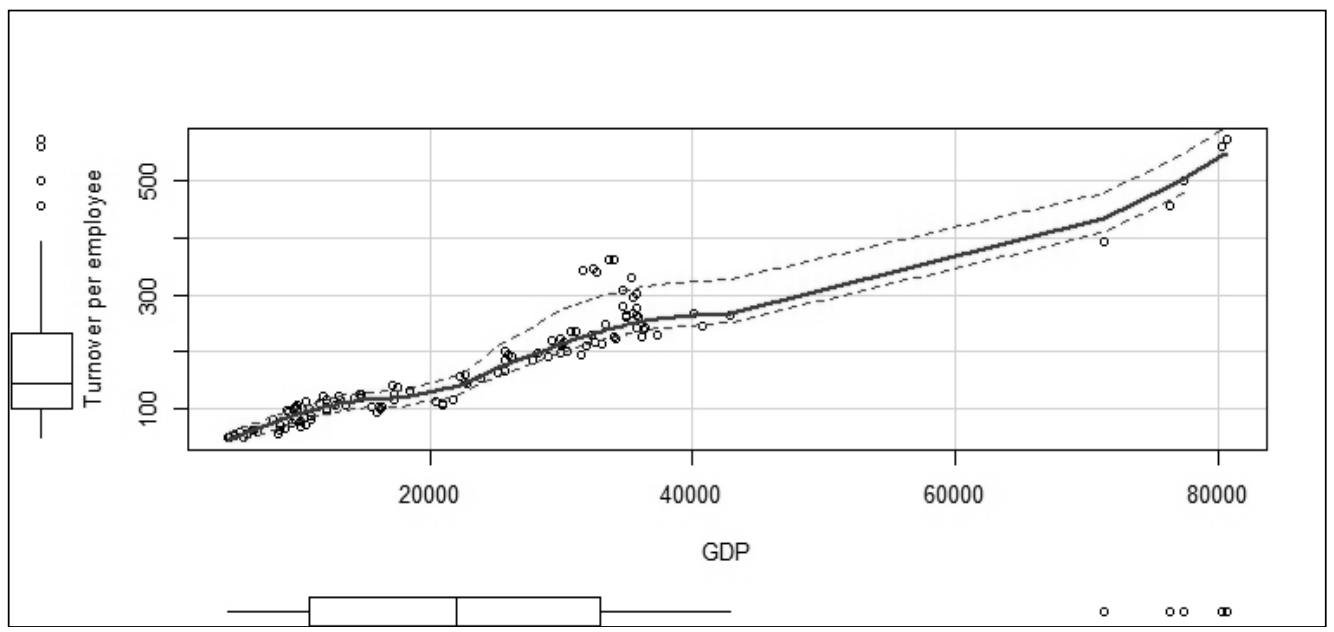

Figure 5: The relation between GDP and labour productivity

The interaction between the two factors, i.e. GDP and KIBS, allows us to build a more efficient model. We can look at the set of countries that displays an average level of the KIBS companies share in total companies (15-20\%) but a low labour productivity (i.e. Romania, Latvia, Estonia, Czech Republic). We can notice that these countries also register 
lower values of GDP per capita than the countries with comparable KIBS levels (i.e. France, Ireland, Finland, Italy, Germany, Belgium) but higher levels of productivity.

\section{Conclusions}

After a long period when the companies in the service sector were considered weak innovators (as compared to those in the manufacturing sector), the last decades have seen a paradigm shift. KIBS is beginning to play a leading role in the knowledge-based economy, as a source of innovation and knowledge in production, dynamic nodes in knowledge-related networks, or intermediaries of innovation between the manufacturing sector as knowledge purchasers, and suppliers, partners and final consumers (Corrocher et al, 2012).

The local authorities and decision-makers have great expectations regarding the role of KIBS in the: regeneration of the economic base of the regions, increase of employment, improvement in the competitiveness and productivity of the SMEs and the role of KIBS in the revival of the entrepreneurial spirit. However, there are several opinions stating that that KIBS sector has its specific way of development and interaction with the economic and social environment. Thus, the possibility of providing remote services seems to encourage more companies located in metropolitan agglomerations and less, the business located in poor peripheral regions or affected by industrial decline; the adaptive capacity of KIBS to regional and sectoral needs is selective. Finally, the impact of these companies for the advance of employment and increase of productivity is unclear and, anyway, below expectations. Thus, we started our research with the purpose of addressing a series of questions regarding the relations between KIBS and the entrepreneurial activity.

Firstly, we have investigated the relation between the share of KIBS companies in total active companies, on one side, and the number of newly registered business per 1,000 inhabitants, each year, on the other side. The results of our analysis failed to support the hypothesis that KIBS act as a stimulating factor of/for the entrepreneurial activity, neither on the level of the whole economy, nor on the regional level of industry (i.e. total industry and manufacturing industry) and construction sector.

Despite the fact that our expectations are derived from the theory regarding KIBS companies as a driver of the entrepreneurial activity, but somehow similarly to other studies, our results are far from being optimistic. Apparently, the correlation between KIBS and entrepreneurship is more complex, as it considerably varies between the investigated EU countries and it registers positive high values only in the case of four countries, i.e. Cyprus, Latvia, Luxembourg and Romania. This suggests that our hypothesis, concerning the fact that innovation taking place at the level of the KIBS companies leads to an increase of the entrepreneurial activity, is not empirically supported. Secondly, we have investigated the impact of KIBS on maintaining companies active (by extending their "life expectancy"). The panel regression analysis yielded a valid model, supporting our hypothesis that KIBS are a blocking factor for the number of closed (discontinued) companies. This effect can be noticed both at the level of the whole economy, and in the case of the analyses conducted on industry, manufacturing and construction sectors. Lastly, we have analysed the relation between KIBS and labour productivity. In this case, we compared two regression models. The first model includes as a factor only KIBS, while the second one includes the combined effects of KIBS and GPD on labour productivity. As expected, the second model is significantly more effective for explaining the variance of the labour productivity. Therefore, the share of KIBS companies in the total number of active companies is a factor of labour productivity. At the same time, the country GDP level together with KIBS density explains up to $47 \%$ of the labour productivity.

In conclusion, we can state that the impact of KIBS on the entrepreneurial activity at the level of the European Union (EU 27, excepting Greece, Denmark and Malta) is mostly of an 
indirect nature. Although no evidence was found that suggests that the share of KIBS companies in the total number of active companies is directly fostering entrepreneurial activity, however, the density of KIBS has been proved to be a factor that prevents the closing down or discontinuing of the companies, as well as a factor which leads to increased labour productivity.

\section{References}

Acs, Z., Braunerhjelm, P., Audretsch, D. and Carlsson, B. (2009). The knowledge spillover theory of entrepreneurship, Small Business Economics, 32 (1), pp. 15-30.

Akehurst, G. (2008,. What Do We Really Know About Services? Service Business, 2 (1), pp. $1-15$.

Agarwal, R., Audretsch, D. and Sarkar, M. (2010). Knowledge spillovers and strategic entrepreneurship, Strategic Entrepreneurship Journal, 4 (4), pp. 271-283.

Audretsch, D. (1998). Agglomeration and the location of innovative activity, Oxford Review of Economic Policy, 14 (1), pp. 18-29.

Audretsch, D. (2012). Entrepreneurship research, Management Decision, 50, pp. 755-764. Audretsch, D. B., Grimm, H. M. and Schuetze, S. (2009). Local strategies within a European policy framework, European Planning Studies, 17 (3), pp. 463-486.

Autio, E. and Acs, Z. (2007). Individual and Country-Level Determinants of Growth Aspiration in New Ventures. In: A, Zacharakis et al., eds. 2007. Frontiers of Entrepreneurship Research, 27. Babson College, MA, USA.

Badulescu, D., Badulescu, A., Sipos-Gug, S. (2018). Knowledge Intensive Business Services and the Entrepreneurial Dynamics. An EU Analysis, presented at the The 21st International Scientific Conference "Enterprise and Competitive Environment", March 2223, Brno, Czech Republic.

Badulescu, D., Badulescu, A., Sipos-Gug, S., Herte, A.D. (2018). How Knowledge Intensive Business Services Foster Entrepreneurial Dynamics and Macroeconomic Performance in European Economies? presented at the The 6th International Conference Innovation Management, Entrepreneurship and Corporate Sustainability (IMES 2018), May 31 - June 1, Prague, Czech Republic.

Casson, M. (2005). Entrepreneurship and the theory of the firm, Journal of Economic Behavior and Organization, 58, pp. 327-348.

Cleveland, W., Grosse, E. and Shyu, W. (1992). Local regression models. In: J. Chambers and T. Hastie, eds. 1992. Statistical Models in S, Chapter 8, Wadsworth \& Brooks/Cole, Pacific Grove, CA, USA.

Corrocher N., Cusmano L., Morrison A. (2012). Competitive Strategies in KnowledgeIntensive Business Services: Evidence from Lombardy. In: Di Maria E., Grandinetti R., Di Bernardo B. (eds) Exploring Knowledge-Intensive Business Services. Palgrave Macmillan, London.

Croissant, Y. and Millo, G. (2008), Panel Data Econometrics in R: The plm Package, Journal of Statistical Software, 27 (2).

Europe Innova (2009). Priority Sector report: Knowledge Intensive Business Services, Stockholm: Center for Strategy and Competitiveness Stockholm School of Economics.

European Commission (2012). Knowledge-intensive (business) services in Europe, Directorate-General for Research and Innovation Capacities, Publications Office of the European Union, Luxembourg.

EUROSTAT (2008). NACE Rev. 2 Statistical classification of economic activities in the European Community, Office for Official Publications of the European Communities, Luxembourg. 
Hatos, A., Hatos, R., Badulescu, A., Badulescu D., (2015). Are Risk Attitudes and Individualism Predictors of Entrepreneurship? A Multivariate Analysis of Romanian Data, Amfiteatru Economic, 17 (38), pp. 48-161.

Hyytinen, A., Pajarinen, M. and Rouvinen, P. (2015). Does innovativeness reduce startup survival rates? Journal of Business Venturing, 30, pp. 564-581.

Karagouni, G. and Kalesi, M. (2011). Knowledge intensive entrepreneurship and dynamic capabilities in low tech SMEs: Evidence from the Greek food sector, MIBES Transactions, 5 (2).

Lever, W. F. (2002). Correlating the knowledge-base of cities with economic growth, Urban Studies, $39(5 / 6)$.

Lumpkin, G. and Dess, G. (1996). Clarifying the entrepreneurial orientation construct and linking it to performance, The Academy of Management Review, 21 (1), pp. 135-172.

Malecki, E. J. (2007). Cities and regions competing in the global economy: Knowledge and local development policies, Environment and Planning C: Government and Policy, 25 (5), pp. 638-654.

Mas-Tur, A. and Ribeiro Soriano, D. (2014). The level of innovation among young innovative companies: the impacts of knowledge-intensive services use, firm characteristics and the entrepreneur attributes, Service Business, 8, pp. 51-63.

Mas-Verdu, F., Wensley, A., Alba, M. and Álvarez-Coque, J.M.G. (2011). How much does KIBS contribute to the generation and diffusion of innovation, Service Business, 5 (3), pp. 195-212.

Merino, F. and Rubalcaba, L. (2013). Are Knowledge-Intensive Services Highly Concentrated? Evidence from European Regions, Tijdschrift voor Economische en Sociale Geografie, 104 (2), pp. 215-232.

Muller, E. and Doloreux, D. (2007). The key dimensions of knowledge intensive business services (KIBS) analysis: a decade of evolution, Working Papers Firms and Region, 1.

Muller, E. and Zenker, A. (2001), Business services as actors of knowledge transformation: the role of KIBS in regional and national innovation systems, Research Policy, 30, pp. 15011516.

Muller, E., Zenker, A. and Ramos, J.-C. (2012)a. Knowledge Angels, Creative Behaviors, and Emerging Innovation Modes: Observations from Alsace, Baden-Wurttemberg, and Catalonia. In: E. Di Maria, R. Grandinetti and B. Di Bernardo, eds. 2012. Exploring Knowledge-Intensive Business Services. Knowledge Management Strategies. Palgrave Macmillan, London, UK, pp. 35-55.

Muller, E., Zenker, A. and Héraud, J.-A. (2012)b. Knowledge Angels: fostering innovation in knowledge-intensive business services through creative individuals. Observations from Canada, China, France, Germany and Spain, http://www.isi.fraunhofer.de/isiwAssets/docs/p/de/publikationen/Muller Zenker Heraud 2012 Knowledge Angels.pdf

[Accessed 2802 2018].

Pe'er, A. and Vertinsky, I. (2008). Firm exits as a determinant of new entry: is there evidence of local creative destruction? Journal of Business Venturing, 23 (3), pp. 280-306.

Rosenbusch, N., Brinckmann, J. and Bausch, A. (2011), Is innovation always beneficial? A meta-analysis of the relationship between innovation and performance in SMEs, Journal of Business Venturing, 26 (4), pp. 441-457.

Savic, M. (2016). What role for knowledge-intensive business services (KIBS) in deindustrialized regions?, Regional Studies, Regional Science, 3 (1), pp. 445-454.

Schnabl, E. and Zenker, A. (2013). Statistical Classification of Knowledge-Intensive Business Services (KIBS) with NACE Rev. 2, Fraunhofer Institute for Systems and Innovation Research ISI, Karlsruhe, Germany.

Shane, S. and Venkataraman, S. (2000). The promise of entrepreneurship as a field of research, Academy of Management Review, 25 (1), pp. 217-226. 
Strambach, S. (2008). Knowledge-Intensive Business Services (KIBS) as drivers of multilevel knowledge dynamics, International Journal of Services Technology and Management, 10, pp. 152-174.

Toivonen, M. and Caru, A. (2016). Prospects and policies in the development of knowledgeintensive business services in Europe. in J.J.M. Ferreira, M.L. Raposo, C.I. Fernandes \& M. Dejardin, eds, Knowledge Intensive Business Services and Regional Competitiveness. Routledge, Routledge Advances in Regional Economics, Science and Policy, pp.301-326. Varis, M., Tohmo, T. and Littunen, H. (2014). Arriving at the Dawn of the New Economy: Is Knowledge-Based Industrial Renewal Possible in a Peripheral Region? European Planning Studies, 22 (1), pp. 101-125.

Wennberg, K. (2010). Entrepreneurship in the knowledge intensive services. In: F. Delmar and K. Wennberg, eds. 2010. The Birth, Growth, and Demise of Entrepreneurial Firms in the Knowledge Intensive Economy, Edward Elgar, Cheltenham, UK.

Wong, P., Ho, T. and Autio, E. (2005), Entrepreneurship, innovation and economic growth: Evidence from GEM data, Small Business Economics, 24 (3), pp. 335-350.

Zieba, M. (2014). Critical Success Factors for Knowledge Management in SMEs in the KIBS Sector, Proceedings of the 15th European Conference on Knowledge Management, The Santarém School of Management and Technology Polytechnic Institute of Santarém, 4-5 September 2014, Santarém, Portugal, 3, pp.1072-1079.

\section{Bio-notes}

Daniel Badulescu graduated at Bucharest University of Economics and currently is Professor and Ph.D. supervisor at the Doctoral School in Economics within the University of Oradea, Romania.

Alina Badulescu is Professor of Economics and Ph.D. coordinator at the Faculty of Economics and Doctoral School in Economics within the University of Oradea, Romania. She graduated Bucharest University of Economics and since she has authored and coauthored numerous journal articles and books.

Sebastian Sipos-Gug graduated at University of Oradea, Faculty of Economic Sciences and now holds a Ph.D at the same University. He is currently working in Romanian banking system.

Anamaria Diana Herte graduated at University of Oradea, Faculty of Economic Sciences and now is Ph.D. student at the same university. In her doctoral research she focuses on the Start-ups in the contemporary economy.

Darie Gavrilut graduated 'Babes-Bolyai' University of Cluj-Napoca, Faculty of Economic Sciences and Business Administration. He is currently a Ph.D. student at University of Oradea. His doctoral research is focused on business innovation, company development and start-up development. 